\title{
Neoliberalismo democrático y una nueva crisis de deuda en Argentina
}

\author{
Democratic neoliberalism and new debt crisis in Argentina
}

Recibido: 16/12/2020 Aprobado: 06/10/2021

Emilia Castorina

Investigadora del CONICET, ${ }^{[1]}$ (Argentina)

DOI: https://doi.org/10.29166/csociales.vli43.2656

ORCID: https://orcid.org/0000-0002-1417-8120

\section{Resumen}

El objetivo central de este trabajo es analizar el modo en que la deuda externa condiciona los procesos de democratización en Argentina en dos niveles interrelacionados: primero, entendiendo el neoliberalismo democrático como una nueva forma de poder y disciplinamiento social; segundo, describiendo brevemente la historia de las crisis de deuda externa en Argentina para ilustrar el poder político del capital financiero.

Palabras claves: Democracia, neoliberalismo, deuda externa, Argentina, crisis.

\begin{abstract}
The main goal of this paper is to analyze the way in which external debt conditions democratization processes in Argentina at two levels: first, by understanding democratic neoliberalism as a new form of power and social disciplining; and second, by briefly capital.
\end{abstract}

Key words: Democracy, neoliberalism, external debt, Argentina, crisis.

\section{Introducción}

La historia del neoliberalismo democrático en Argentina está marcada por crisis de deuda externa recurrentes y cíclicas, las cuales no son más que síntomas de una contradicción profunda entre el poder financiero (global y local) y la democracia. La hiperinflación, en 1989, forzó la salida anticipada del gobierno de Raúl Alfonsín (1983-1989), la crisis del 2001 terminó con el gobierno de Fernando De la Rúa (1998-2001), y Mauricio Macri (2015-2019) es el primer presidente de la historia argentina en perder una re-elección en medio de fuertes corridas cambiarias, fuga de capitales y un endeudamiento con el FMI sin precedentes históricos. El objetivo central de este

1 Ph. D. en Ciencia Política, York University, Canadá. Investigadora del CONICET, Argentina y docente de la Universidad de Buenos Aires. 
trabajo es analizar el modo en que los ciclos de endeudamiento condicionan los procesos de democratización en Argentina, en dos niveles de análisis interrelacionados.

Primero, es importante comprender que el neoliberalismo a nivel global se caracteriza por generar crisis financieras recurrentes, las cuales no son una anomalía ni el preanuncio de su fin sino un aspecto clave de su mecanismo de funcionamiento. Como afirman algunos críticos en economía política internacional (Harvey, 2003; Gowan, 1998; Rude, 2005; Panitch y Gindin, 2004), la valorización financiera se reproduce a través de las crisis en la medida en que éstas no solo representan oportunidades únicas para socializar los riesgos, sino también para reestructurar las políticas económicas y reorganizar las relaciones sociales de producción «a fin de profundizar aún más la concentración y la internacionalización de la producción» (Harvey, 2003, p. 67). No es un dato menor que dos tercios de los miembros del FMI hayan experimentado crisis financieras después de 1980, algunos incluso tres veces como la Argentina, habilitando así los famosos «rescates financieros» del FMI que no son más que planes de ajuste para distribuir los costos de las crisis lejos del capital financiero y hacia los sectores de menos ingresos (Stiglitz, 2009). Así, lo que aparentan ser «fracasos» de la economía neoliberal son en realidad síntomas de una estrategia eventualmente exitosa del capital sobre el trabajo, ya que cada reestructuración económica profundiza la debilidad estructural y organizativa de los trabajadores. De esta manera, las crisis financieras y en general la inestabilidad o inseguridad económica han sido funcionales al disciplinamiento social en la medida en que los países periféricos y las clases trabajadoras en general son sistemáticamente responsabili- zadas por las causas de las crisis - ya sea por el excesivo gasto social, los altos salarios o el exceso de demandas sociales sobre el Estado (Gowan, 1998). En otras palabras, no se puede comprender la nueva crisis de deuda en Argentina si no se interpreta adecuadamente qué es el neoliberalismo democrático. En efecto, no se trata de un mero sistema económico, sino de una nueva forma de poder (Castorina 2017, 2018 ), un verdadero proyecto político exitosamente instaurado desde la llamada «revolución conservadora» por las nuevas elites financieras globales - los nuevos «amos de la humanidad» (Chomsky, 2015). ${ }^{[2]}$

Segundo, en la triste historia de la integración de Argentina al mundo a través de los mercados financieros se inscribe un nuevo capítulo (2015-2019) de la lógica coercitiva con la que el llamado «nuevo constitucionalismo» (Gill, 2003) — los condicionamientos, acuerdos y marcos regulatorios dentro de los cuales se institucionalizan políticas fiscales y monetarias coordinadas por el FMI, el Departamento del Tesoro y la Reserva Federal de EE. UU., el Banco Mundial y una densa red de instituciones financieras internacionalesy su nuevo rehén por elección, el gobierno de Mauricio Macri, llevaron al Estado argentino a un nuevo default financiero y a una crisis social y económica profunda. El gobierno de la Alianza Cambiemos (PRO, UCR y CC) fue un verdadero proyecto de reacción y restauración conservadora basado en la intención explícita de reconfigurar el Estado argentino para facilitar la concentración de la riqueza, la internacionalización del capital (fundamentalmente en base a procesos de valorización financiera y no mediante capitales de inversión directa y productiva) y el consiguiente disciplinamiento de los sectores trabajadores mediante los sala-

2 El disciplinamiento neoliberal se inscribe dentro de la histórica relación Norte-Sur, en donde el imperialismo norteamericano ha buscado ejercer su dominio sobre Sudamérica a través de distintas estrategias: intervencionismo directo; Plan Cóndor, Doctrina Monroe, Consenso de Washington, Alianza del Pacífico, OEA (Org’anización de Estados Americanos), etc. 
rios y la criminalización de la protesta y la pobreza $^{[3]}$. Pero las nuevas políticas económicas de ajuste y endeudamiento no solo le hicieron perder la reelección al presidente argentino, sino que agravaron la debilidad estructural de la economía argentina para afrontar pagos soberanos. En este sentido, un breve análisis de la historia de la deuda externa argentina y sus sucesivas crisis, a través de sus hits financieros — «convertibilidad» (1991-2001), «blindaje»y «megacanje» (2001), «corralito» (2001), default (2002), «cepo cambiario» (2014), «fondos buitres» (2015) y el nuevo «reperfilamiento» de la deuda (2019) — sirve para ilustrar el verdadero poder político del capital financiero, el cual obtiene ganancias extraordinarias sin ningún tipo de responsabilidad social sobre las consecuencias que genera.

\section{Neoliberalismo democrático y poder financiero}

Dentro de las formas históricas de capitalismo, el neoliberalismo democrático se basa en una forma novedosa de interpretar y «resolver» las contradicciones inherentes al capitalismo. La llamada revolución conservadora de los años setenta y ochenta en el mundo tuvo un diagnóstico casi unánime: las contradicciones entre capitalismo y democracia eran producto de un «exceso de democracia», entendida en términos sociales y distributivos por sobrecargar al Estado con altos déficits y a la economía con altos niveles de inflación según lo retratara el clásico Informe de la Comisión Trilateral (Crozier, Huntington y Watanuki, 1975). Con el ascenso de nuevas elites financieras dentro de los mercados globales se transformó la dinámica de la valorización del capital, esto es, el capital ya no se alimentaría de la riqueza creada por el trabajo sino del «valor financiero» que deriva de la especulación con el cambio de divisas, las cotizaciones bursátiles, los créditos, las hipotecas, los fondos de pensiones e inversiones, etc. La liberalización e internacionalización de las finanzas globales se situó en el corazón mismo del proceso de acumulación ya que el salario dejó de ser el eje central del sistema para dejar en su lugar al interés especulativo, el cual genera más liquidez con menor costo humano y social directo. Esto permitió transformar cómodamente la crisis de los 70, que era una crisis del capital, en una crisis del trabajo (Arrighi, 2001) apuntando directamente a los beneficios sociales de los trabajadores y a su capacidad organizativa para politizar sus demandas. Se instauró así un modus operandi que continúa hasta nuestros días: desplazar los costos de las crisis hacia los sectores más desfavorecidos, lo que se conoce como socialización del riesgo o, dicho en otros términos, siempre culpar a la víctima. En definitiva, la solución neoliberal supondría reducir la democracia en favor del capitalismo concentrado y financiero.

Este proceso indica un cambio en la $a c^{-}$ countability del gobierno (el control democrático) del «pueblo» a los mercados, esto es, los intereses y sentimientos de inversores, acreedores e instituciones financieras. Esto quiere decir que las grandes empresas que dominan los mercados se han convertido en las protagonistas privilegiadas de las democracias. Como asegurara en una famosa entrevista el magnate norteamericano de origen húngaro, George Soros, «los mercados votan todos los días». ${ }^{[4]}$ Es decir, que el mandato del «demos» poco tiene que ver con lo que los magistrados electos efectivamente habrán de hacer. Como afirma Borón, de eso se encarga el «otro poder», el mercado, cuyos pocos y muy selectos participantes (las grandes instituciones financieras y los gran-

3 Para ver en mayor detalle los distintos aspectos de este proyecto, consultar VV. AA., «Macri: por todo como sea», en Márgenes, revista de economía política, N. ${ }^{\circ}$, octubre 2018 , UNGS.

4 Entrevista en el diario italiano La República, 28 de enero de 1995. 
des conglomerados económicos) que hacen oír su voz todos los días —en la bolsa de valores, en la cotización del dólar o mediante una fuga de capitales - y «cuyas decisiones y preferencias son más tenidas en cuenta por los gobiernos que las de los electores porque éstos saben que difícilmente podrán resistir más de unos pocos días a las presiones y las extorsiones del capital» (2000, p. 116). De esta manera, el mercado instituye un segundo -y más privilegiado- mecanismo decisorio: «un sistema de voto calificado, esencialmente antidemocrático, y aislado por completo de los flujos y demandas que pudieran proceder del ciudadano común y corriente»(Boron, 2000, p. 116).

Esta desigualdad en la forma en que las preferencias de los ciudadanos y las grandes empresas logran traducirse en políticas públicas, tiende progresivamente a agravarse en la medida en que los procesos electorales se vuelven cada vez más costosos y los partidos políticos se vuelven cada vez más dependientes del financiamiento de las grandes empresas para sus campañas, lo cual les asegura a estas últimas políticas económicas afines a sus intereses. La viabilidad de la democracia dentro del neoliberalismo depende entonces de que las instituciones democráticas se mantengan dentro de límites estrechos. En términos de Przeworski (1995), para que la democracia sea estable el gobierno debe ser lo suficientemente fuerte como para gobernar con efectividad, pero al mismo tiempo lo suficientemente débil como para no gobernar en contra de ciertos intereses fundamentales.

En este sentido, podemos definir al neoliberalismo democrático como un proyecto político en el que el capital concentrado busca evitar la participación, intrusión, o lo que se denomina eufemísticamente «intervención», de la mayor parte de la población en el proceso de toma de decisiones económicas. Los Estados neoliberales, lejos de «no intervenir en la economía», se muestran muy activos y comprometidos en garantizar «climas favorables de inversión» que privilegian casi siempre las prerrogativas empresariales por sobre los derechos colectivos de los trabajadores, o favorecen la integridad o solvencia de los sistemas financieros a expensas de otros sectores de la población (Harvey, 2005; Panitch, 1994). Mientras los ciudadanos comunes se vuelven «apolíticos» y rechazan toda «intervención del Estado» en la economía, las grandes empresas se politizan cada vez más y están muy activas a la hora de hacer lobbies con el Estado y asegurar sus derechos de acumulación. En el neoliberalismo democrático, la separación de las clases trabajadoras del proceso de toma de decisiones de la economía tiene lugar sin la necesidad de que éstas pierdan derechos políticos como en la época del liberalismo clásico del siglo XIX, y así el poder político tiende progresivamente a privatizarse (Wood, 1995). Esto quiere decir que las grandes empresas no solo se desligan de la responsabilidad de garantizar condiciones materiales dignas para su fuerza de trabajo, sino que, además, la reproducción social de las sociedades en general está crecientemente mercantilizada y, en última instancia, ligada a estructuras lejanas (como suelen ser los fondos de inversión) sobre las cuales la población tiene poco control.

En la medida en que los gobiernos endeudados, como el argentino, están más controlados por los capitales financieros transnacionales que por sus propios ciudadanos, estos regímenes tienden a ser rehenes del «nuevo constitucionalismo», en tanto que estos acuerdos y condicionamientos económicos parecieran tener más peso y poder que las reglas formales (y las constituciones) de la mayoría de dichos países. Las instituciones financieras internacionales operan a nivel global como un nuevo "panóptico» (Gill, 2003) en el que dichos organismos pueden intervenir, moni- 
torear y controlar las políticas económicas de gran parte de los países endeudados mediante una serie de coerciones y condicionamientos que estos nuevos regímenes (generalmente se trata de democracias jóvenes endeudadas durante gobiernos autoritarios) no tienen el poder de refutar, y el precio de no hacerlo está más allá de sus capacidades o de su voluntad $^{[5]}$. Por lo tanto, cuando la democratización se presenta como el triunfo de la libertad individual frente a la coerción del Estado, en realidad, lo que se legitima sutilmente es la coerción del mercado, el cual puede ser mucho más opresivo y autoritario que algunos déspotas políticos. De hecho, ningún déspota antiguo hubiera soñado con penetrar de manera tan minuciosa y efectiva las vidas de sus súbditos — sus elecciones, preferencias, opiniones y relaciones - como el mercado, cuyos imperativos de competencia y rentabilidad tienen una fuerza coercitiva suficiente para reducir todos los valores y relaciones sociales a mercancías (véase Wood, 1995, p. 295). En la nueva era digital, todo esto parece potenciarse y perfeccionarse a través de las redes sociales y el uso de Big Data por parte de gobiernos y partidos políticos en tiempos electorales, como quedó en evidencia recientemente con la escandalosa asociación de Facebook y Cambridge Analytical para influenciar en varios procesos electorales, incluso el de 2015 en Argentina.

En este sentido, el neoliberalismo democrático puede ser visto como un intento hegemónico (Gramsci), más o menos exitoso, del capital concentrado por articular los muchos intereses de otros grupos sociales a los propios, presentando las ventajas del mercado frente al Estado como el interés universal de la sociedad como un todo. La «dirección moral e intelectual» de estos sectores se vuelve efectiva en la medida en que clases medias y trabajadoras aspiran a todos los niveles de estatus y consumo disponibles, lo cual puede observarse en al menos tres niveles: 1) el desplazamiento progresivo del ciudadano por el consumidor, donde el ciudadano se despolitiza y se desconecta del poder y la participación política; 2) el modo en que pequeños ahorristas, trabajadores y consumidores en general se ligan perversa y jerárquicamente (desigualmente) al éxito o fracaso de las estrategias de valorización de los sectores más concentrados del capital bajo la forma de fondos privados de inversión, jubilación y / o pensión (Duménil y Lévy, 2002, p. 3) una interpretación individualista del bienestar, los derechos sociales y la pobreza, donde predomina la tendencia a individualizar los problemas sociales y las respuestas a los mismos, particularmente mediante políticas sociales focalizadas (y no universales) contra la pobreza. Así, el neoliberalismo democrático se basa en una novedosa justificación de la desigualdad social y la pobreza, donde el bienestar ya no es visto como un derecho social, sino un problema de oportunidades individuales, de donde se deduce que la pobreza es el producto de las capacidades o conductas individuales cuya resolución no depende de las políticas de Estado.

\section{Deuda externa y crisis recurrentes en Argentina}

La primera crisis de deuda neoliberal en Argentina empezó en 1982 cuando la dictadura militar, no un gobierno elegido democráticamente, estatizó la deuda de privados (fundamentalmente bancos estadounidenses y británicos, y algunas grandes empresas nacionales) que había crecido de USD 7.000 millones a USD 46.000 debido a que la Reserva Federal de EE. UU.,

5 Algunos trabajos, alternativamente, llaman a este proceso «gobernanza neoliberal» o «debtocracia» (debtocracy), término originalmente empleado para describir el poder que ejercen los mercados sobre los Estados a partir de la liberalización del mercado de deuda soberana, ver, por ejemplo, Angelis, M. (2003). 
bajo el liderazgo de Paul Volcker, subió las tasas de interés hasta un $20 \%$ provocando una crisis de endeudamiento en América Latina y el resto del mundo en desarrollo. La reprogramación de esta deuda derivó en una crisis de hiperinflación en 1989 ante los sucesivos fracasos de la política económica del primer gobierno democrático para frenar la inflación, la cual llegó a $3000 \%$, desencadenando un incumplimiento de deuda y el traspaso anticipado del poder al peronista Carlos Menem. Si bien el nuevo gobierno redujo la inflación y la economía logró salir momentáneamente de la recesión, aumentó la deuda externa a más de USD 100.000 millones.

El mecanismo de endeudamiento argentino durante los 90 es paradigmático. Por un lado, la estrategia de crecimiento económico que se implementó con la convertibilidad cambiaria ( 1 peso $=1$ dólar) era estructuralmente problemática en la medida que generaba déficit crónico de la balanza comercial (debido a la combinación de liberalización/ apertura económica con apreciación del tipo de cambio), el cual solo podía subsanarse con inversiones de capital fundamentalmente extranjero. Esta dependencia respecto a las inversiones hacía estructuralmente vulnerable a la economía argentina a las demandas de las grandes empresas que ponían como condición para invertir toda una serie de políticas de Estado, eufemísticamente definidas como «garantías jurídicas» para generar «climas propicios o transparentes de inversión». En realidad, estas demandas se traducían, y el presidente Carlos Menem estaba más que dispuesto a otorgarlas, en políticas de flexibilización laboral, reducción de impuestos corporativos y recortes del gasto público que poco tenían que ver con las garantías jurídicas de la mayoría de la población, y sí con las prerrogativas de rentabilidad de las grandes empresas transnacionales. Por otro lado, en el contexto de la convertibilidad era imposible cumplir con las obligaciones de deuda con base en la capacidad productiva propia de la economía (o mediante divisas generadas por las exportaciones), por lo tanto, Argentina entró en un círculo vicioso de pagar deuda con más deuda que, a una tasa de interés promedio anual de $12 \%$, entre 1990 y 2000, solo logró perpetuarla. La economía argentina se volvió más dependiente de los préstamos del FMI para cumplir con sus obligaciones, lo que implicaba al mismo tiempo, volverse más vulnerable a los condicionamientos y los requerimientos del FMI (y del nuevo constitucionalismo en general). La coerción se manifestaba así en que la deuda externa solo podía pagarse a través de ajustes del gasto social y público, es decir, ajustes a la calidad de vida de la mayoría de la población mediante recortes en la salud, la educación, los salarios, y un paquete de privatizaciones de empresas públicas que implicaban no solo una transferencia de ingresos de los sectores populares hacia los sectores más concentrados de la economía, sino un verdadero «tributo imperial» (Boron, 1995) en la forma de rentas del petróleo, el agua y las comunicaciones. En esto consistía el Plan Brady para pagar los servicios de la deuda, que Argentina negociara en 1992 con el secretario del Tesoro norteamericano Nicholas Brady, el cual demandaba un intercambio masivo de deuda por empresas públicas valuadas muy por debajo de su valor real (véase para más detalle, Azpiazu, 2002).

Esta estrategia de desarrollo en Argentina resultó en una contradicción creciente entre el poder estructural de los sectores concentrados de la economía y las capacidades para la reproducción social de la mayoría; una disociación progresiva entre crecimiento económico y bienestar social debido a la distribución despareja de los costos del endeudamiento externo. Hacia 2001, la deuda externa ascendía a USD 128.000 millones y el gobierno de De La Rúa (1999-2001) decidió 
hacer recortes del 13\% en salarios públicos y jubilaciones frente a la negativa del FMI de realizar un nuevo préstamo para afrontar servicios de deuda si no se lograba bajar el déficit. El gobierno, además, impuso un «corralito» financiero a los depósitos bancarios de la población para salvar a los bancos, luego de haber dejado durante un año que las grandes empresas e inversores sacaran sus capitales ante un inminente default de la economía. Esta fuga previa al default fue posible gracias a que el gobierno de De la Rúa implementó dos mecanismos financieros, el blindaje y el megacanje. En efecto, en enero de 2001 Argentina recibió un crédito por USD 40.000 millones para «blindar» su economía ante la necesidad de cancelar sus compromisos financieros internacionales. A cambio, el gobierno se comprometía, entre otras cosas, a desregular las obras sociales y a recortar las jubilaciones futuras. Según el FMI, el blindaje, traería inevitablemente una lluvia de inversiones extranjeras (y, por lo tanto, dólares para sostener la paridad cambiaria) ante las señales de voluntad del gobierno argentino de pagar sus deudas a cualquier costo. Sin embargo, detrás del blindaje no solo estaban la especulación financiera y el sobreendeudamiento ya que el Estado era un mero "pasamanos» de dichos créditos, sino la «intervención» creciente del FMI en el control, diseño y ejecución de la política económica doméstica. De hecho, y como condición para gestionar los nuevos créditos, el FMI no solo tomaba las atribuciones del poder Ejecutivo, sino que también condicionaba al Parlamento. El número dos del FMI, Stanley Fischer, se ocuparía personalmente de instar al Parlamento argentino a ratificar las reformas pedidas por dicho organismo que habían sido hasta entonces solo implementadas por decreto.
Ante el fracaso inminente del blindaje, que no resolvió ninguno de los problemas de la economía argentina, sino que los agravó ya que no atrajo ninguna inversión extranjera, el gobierno implementaría el segundo, y aún más escandaloso, mecanismo financiero: el megacanje. Para dicho fin tuvo que cambiar al ministro de Economía, volviendo a nombrar al exministro de la Convertibilidad, Domingo Cavallo. Este megacanje buscaba aliviar el pago de intereses y de capital de la deuda externa, canjeando la deuda por una nueva que permitiera pagar en un plazo mayor. Esta propuesta, que tenía un costo exorbitante y aumentaba la deuda de manera exponencial, provenía del banquero y ex secretario del Tesoro norteamericano, David Murdorf, quien para entonces era el CEO del banco Credit Suiss y amigo personal de Cavallo. El canje de 46 tipos distintos de bonos de deuda por 5 tipos de bonos con vencimiento en 2031, significaron un aumento de la deuda en alrededor de USD 55.000 millones, donde además siete bancos cobraron comisiones por 150 millones de dólares y Murdorf alrededor de USD 20 millones. Los bancos y las AfjPs (Administración de Fondos de Jubilaciones y Pensiones) aportaban al canje títulos por USD 27.000 millones de dólares para ser canjeados por los nuevos papeles de deuda. Sin embargo, 20.000 de esos 27.000 ya estaban en las carteras de esos bancos y las AfjPs, por lo tanto, cobraron comisiones por hacer de intermediarios financieros de ellos mismos. ${ }^{[6]}$

Las contradicciones estallaron en diciembre del 2001 cuando se volvieron políticamente inmanejables, esto es, cuando ante la expropiación financiera y el empobrecimiento masivo (el desempleo aumentó de $6 \%$ en 1991 a cerca del $20 \%$ en 2001 , el índice de pobreza pasó de $16 \%$ en 1991 a $54 \%$ en 2002),

\footnotetext{
6 Si bien 8 funcionarios del gobierno de De la Rúa, Cavallo y el propio Murdorf (quien nunca pudo ser traído a declarar frente a la justicia argentina) fueron procesados por la mayor estafa financiera de la Argentina, en 2014 la causa prescribió y todos fueron absueltos (véase Brown, «Blindaje y Megacanje», 2014).
} 
la mayoría de la población se encontró sin canales institucionales donde hacer oír su voz y sus reclamos, saliendo masivamente a las calles y forzando por primera vez la caída de un gobierno democrático. Sin duda, la crisis del 2001 fue la peor crisis financiera, política y social de la historia argentina, sin embargo, el neoliberalismo democrático resultó ser bastante efectivo para recomponer y reestructurar la acumulación utilizando su mecanismo distintivo: la politización despareja de la sociedad. En efecto, mientras los movimientos sociales hacían catarsis (utilizando la expresión de Gramsci) en las calles, los bancos y las grandes empresas hacían catarsis en el Parlamento aprobando una serie de leyes y rescates financieros durante el breve gobierno de Duhalde (2002-2003). Mientras la población manifestaba pidiendo la devolución de sus ahorros expropiados por los bancos, la clase capitalista hizo negocios gracias a las políticas de gobierno que le permitieron transferir los costos de la salida de la convertibilidad cambiaria a la población. En efecto, la devaluación de la moneda no solo se tradujo en una depreciación inmediata de los salarios y un aumento del costo de vida para la mayoría de los ciudadanos, las grandes empresas pudieron pesificar y, así, licuar sus deudas. Si la devaluación tuvo un efecto inmediato negativo para la población en general, para los sectores concentrados de la economía resultó ser un gran negocio: ahora podían pagar sueldos y deudas en pesos devaluados mientras sus activos permanecían en dólares gracias a la fuga previa de capitales.

En 2005 Argentina abrió un nuevo capítulo en su historia de la deuda externa. El gobierno de Néstor Kirchner (2003-2007) se propuso reestructurar la deuda como condición fundamental para salir de la crisis, con la determinación de encarar una nueva etapa de desarrollo y crecimiento económico que no estuviera atado al endeudamiento. Por un lado, se refinanciaron a tres años USD 21.000 millones con organismos multilaterales con base en una reducción de la tasa de interés, y USD 9.500 millones se pagó en efectivo al FMI. Por el otro, la gran mayoría de la deuda privada también se renegoció: Argentina les ofreció a los tenedores de bonos una quita del 70\% la cual fue aceptada por el 76\%, y en un nuevo canje ofrecido en 2010 entraron hasta el 92\% de los bonistas (véase La Nación, 2005). Desde entonces, Argentina pudo cumplir con todos sus compromisos financieros con base en un esquema de crecimiento económico más sustentable que el de la década anterior basado en las exportaciones (y en un tipo de cambio competitivo) y una incipiente sustitución de importaciones que le permitió reactivar el sistema productivo local y, por lo tanto, el mercado interno, generando a su vez recursos para invertir en políticas sociales de asistencia a los sectores más castigados. Como resultado, Argentina pudo alcanzar durante un tiempo altas tasas de crecimiento $(9,2$ en 2005 ; 8,4 en 2006) y aumentar sus reservas en dólares con base en una fórmula poco común dentro del neoliberalismo democrático: reducción de la deuda en relación al PBI sin ninguna clase de acceso al crédito internacional y, en definitiva, sin ninguna intervención del FMI o el BM; es decir, emancipada por default del «nuevo constitucionalismo».

Argentina se convirtió entre 2005 y 2015 en una suerte de «oveja negra» del sistema financiero internacional por ser el contraejemplo de mucho de lo que predicaban las instituciones financieras internacionales en materia de deuda externa, particularmente, por intentar salirse del círculo vicioso que perpetúa la deuda, del rol de deudor eterno que facilita los «climas propicios de inversión» y las estrategias de control que éstas involucran. Y efectivamente, en 2014, en el último tramo del gobierno de Cristina Kirchner (2007-2015), la Argentina encontró un importante revés en su 
estrategia de desendeudamiento tras un fallo judicial de un juez de Nueva York. El mismo reconocía el reclamo de unos llamados «fondos buitres» que habían comprado bonos en 2008 que no habían entrado al canje de 2005 y 2010 por USD 428 millones y ahora se les permitía cobrar USD 1500 millones (solo por intereses y punitorios). Lo polémico del fallo no es solo esta ganancia escandalosa para el $1 \%$ de los tenedores de deuda argentina sino las implicaciones de cumplir con este pago: en función de la cláusula Rufo de los bonos reestructurados en 2005 y 2010, si el 1\% cobra más que el resto, el otro 99\% está habilitado para reclamar un pago igual, aumentando así la deuda en USD 15.000 millones, lo cual pondría en jaque cualquier estrategia sostenible de crecimiento para la economía argentina (véase F. Poli para La Nación, 2014).

En este contexto, los fondos buitres demostraron un alto poder político al condicionar el proceso de negociación con el Estado argentino, logrando que el juez Thomas Griesa impida el pago a los bonistas que debían cobrar dentro del esquema de pagos que Argentina tenía previsto desde 2005 si no se cumplía con el fallo, tal y como estaba estipulado, dejando a la Argentina en un nuevo default (técnico). Ante esta coerción financiera, el nuevo gobierno de Mauricio Macri en 2016 finalmente terminó pagando USD 9300 millones a los fondos buitres con el pretexto de «volver a los mercados de capitales», es decir, volver a entrar a los condicionamientos fiscales y monetarios del nuevo constitucionalismo. Los fondos buitres son una expresión radicalizada del poder financiero global y particularmente poderosa. Se trata de fondos de capital de riesgo que invierten en el mercado de deuda de Estados y empresas al borde de la quiebra en base a la especulación ya que compran a precio módico (o muy inferior a su valor nominal) deuda de países pobres con profundas crisis económicas y financieras con el fin de litigar en los foros internacionales para obtener hasta el 100\% del valor de deuda original. Estos fondos buitres no podrían existir si hubiera una legislación que los limite y, muy por el contrario, son amparados por la legislación y la justicia norteamericana. En su momento, el Nobel de Economía J. Stiglitz fue categórico respecto al fallo de Griesa contra Argentina, «nunca entendió la complejidad del caso argentino» señalando además que no se «debería confiar en la imparcialidad y competencia del poder judicial de Estados Unidos» para estos litigios (véase Stiglitz, 2014). En palabras de T. Piketty, Argentina fue víctima del «heg’emonismo jurídico norteamericano", el cual puede ser «peor que la ausencia de justicia» ya que se trata de «una suerte de privatización del derecho con fondos financieros e intereses financieros que construyen su propio derecho, sus propias cortes de arbitraje, sus propios tribunales» (Página 12, 2014).

$\mathrm{Y}$ es que se trata de grupos altamente politizados, debido a que tienen un altísimo poder de lobby en los tres poderes del Estado norteamericano y en los medios de comunicación globales. Y cuando no operan a nivel local en EE. UU. encuentran en organismos como el CIADI (Centro Internacional de Arreglo de Diferencias Relativas a Inversiones), una institución del Banco Mundial con sede en Washington, un ámbito de presión de carácter internacional. En el caso argentino, el principal fondo involucrado es el NML Capital, dirigido por Paul Singer, un multimillonario de Wall Street con muchísimo poder político, ya que es el principal financista del partido Republicano. A través de su fondo NML Capital, Singer pagó 177 millones de dólares por todos sus bonos argentinos y recibió 2426,6 millones de dólares: una rentabilidad global de 1270 por ciento. Esta extraordinaria ganancia alcanzó para que Singer defina a Macri como 
«el campeón de las reformas económicas» en la revista Time (Lukin, Página 12, 10 de septiembre de 2019).

A partir de la cancelación de la deuda con los fondos buitres, desde 2016 se dio inicio a una nueva etapa de endeudamiento externo como eje estratégico del desarrollo económico y, como consecuencia, una nueva socialización del riesgo sobre esa deuda. $\mathrm{Du}$ rante 2016 y 2017, la Alianza Cambiemos, convirtió a la Argentina en un verdadero paraíso financiero gracias a la emisión de deuda mediante letras del Banco Central (LEBAC), presidido no casualmente por uno de los responsables procesados por el Megacanje anterior, Federico Sturzzeneger. Estas letras pagaban una tasa del $38 \%$ : los bancos recibían el dinero de los plazos fijos de sus clientes por los que pagan alrededor del $27 \%$ anual y con ese dinero compraban LEBAC a 35 días cobrando el equivalente al 38 o $40 \%$ anual. Por un simple pase sin riesgo ganaban entre 11 y 13 puntos. También se podían suscribir LEBAC en dólares, que pagaba la increíble tasa del $20 \%$ anual en dólares. Como el gobierno había levantado todas las restricciones a la entrada de capitales golondrinas que durante los gobiernos kirchneristas los obligaba a permanecer un año en el país, los capitales podían traer dólares, venderlos, invertir en LEBAC, y cobrar en 35 días la diferencia de alrededor de 10 puntos en dólares. Una tasa imposible de encontrar en ningún lugar del planeta y por lo tanto una nueva etapa de fuga de capitales (Zlotowiazda, 2016). Mientras el capital financiero estaba eufórico, la economía argentina entraba en recesión ya que la tasa de interés de LEBAC desincentivaba completamente la inversión para actividades productivas. Con un endeudamiento del Estado a través de las LEBAC de 500.000 millones de pesos (Presman, 2016) solo en 2016, comenzaron a abrirse una serie de interrogantes acerca de la solvencia del BCRA para cumplir con el volumen de cancelaciones y de la sustentabilidad a mediano y largo plazo del Estado argentino. Según un informe del Observatorio de Políticas Públicas de la Universidad Nacional de Avellaneda (enero 2017), el peso de la deuda en LEBAC proyectaba que para el año 2017 podría llegar al 14,7\% del PBI, lo cual hacía evidente la escasa sustentabilidad de la deuda. En efecto, el monto de la deuda medida en dólares suponía un promedio de USD 64.600 millones, es decir, un monto mucho mayor al total del financiamiento externo que el gobierno nacional esperaba tomar en 2017 (USD 42.000 millones). Esta diferencia preanunciaba el peligro a corto plazo.

Efectivamente, en abril de 2018 la bomba financiera de las LEBAC comenzó a explotar cuando los tenedores extranjeros empezaron a desarmar sus posiciones en estos bonos y se desató la corrida cambiara que llevaría el dólar de 20 a 40 pesos en pocos días. ${ }^{[7]}$ Frente a la megadevaluación y la fuga de divisas que el BCRA no lograba contener (USD 13.000 durante la dirección de Sturzenegger y USD 14.000 posteriores con su sucesor, Caputo), el gobierno de Cambiemos tuvo que acudir de emergencia al FMI, con el cual acordó el stand by más grande de la historia del organismo (USD 57.000 millones, $61 \%$ del total de sus créditos). La llegada del FMI, que no gravitaba en la economía argentina desde que Néstor Kirchner había cancelado deuda en 2005, no solo incrementó el peso del endeudamiento sino también un fuerte condicionamiento sobre el accionar de la política económica

7 Según algunos analistas, el disparador de todo fue la puesta en vigencia del impuesto a la renta financiera por parte del Congreso, que afectaba la tenencia de LEBAC de fondos especulativos del exterior, que salieron del mercado (Juan Pablo Alvarez, «Cómo comenzó la megadevaluación de 2018 que lo cambió todo en Argentina», diario Perfil, 25 de abril, 2019). 
del gobierno en la forma de metas fiscales, es decir, ajustes a los sectores de siempre, que resultaron en un agravamiento de la crisis económica: la inflación más alta desde 1992 $(53,9)$, aumento del desempleo y la pobreza (38\%). Como consecuencia, no solo el poder financiero comenzó a perder rápidamente la confianza en el programa de reformas, sino que Macri perdió casi todo su capital político, y la combinación de estos dos factores sería letal, tal como quedó demostrado en las PASO (primarias abiertas y obligatorias) del 11 de agosto de 2019. La fuerte derrota electoral aceleró la fuga de capitales, una nueva corrida cambiaria y el desenlace en un "default anunciado", según titularía el Financial Times. Según el Observatorio de Deuda Externa (ODE) se emitió USD 187.298 millones de deuda. De ese total, el 71,2\% ya se perdió en concepto de fuga de capitales, y de lo que desembolsó el FMI ya se perdió el $82,6 \%$. Según gran parte de los analistas, el FMI estuvo en realidad "financiando la fuga de capitales especulativos que entraron en los primeros años de gobierno» durante este último año. ${ }^{[8]} \mathrm{El}$ riesgo país promedia los 2200 puntos desde las elecciones, y en un contexto de estanflación no parece haber perspectiva inmediata de pago soberano. Esto explica el llamado «reperfilamiento» de deuda anunciado por el gobierno y un nuevo «cepo» cambiario (control de capitales).

Vale la pena detenerse a analizar lo que pasó en Argentina el 12 de agosto, el día después de las elecciones primarias, que dieran como favoritos a los Fernández (Alberto Fernández y Cristina Fernández de Kirchner): una evidencia de las contradicciones entre la democracia y el poder de los mercados financieros. El domingo 11 votaron los ciudadanos, el lunes 12 votaron lo mercados. Los primeros le dijeron NO al programa de ajuste y endeudamiento, los segundos dijeron NO a los primeros. La fuga de los capitales financieros especulativos puso en jaque a toda la economía argentina con tal de no asumir ningún costo o responsabilidad social por sus ganancias extraordinarias, no solo por la vulnerabilidad estructural de la macroeconomía argentina sino también por la dinámica extorsiva con que el poder financiero opera en el mundo, en general, y en Argentina en particular. En primer lugar, tanto la prensa financiera mundial y local, como el presidente Macri culparon a los ciudadanos por votar mal. Literalmente, el presidente en conferencia de prensa aseguró: «los mercados no confían en el rumbo que quieren seguir los argentinos» y ordenó a las autoridades del BCRA que no intervinieran en el mercado cambiario dejando correr la subida del valor del dólar (de 45 a 60 pesos en solo una jornada) para aleccionar a los electores. En segundo lugar, el «voto calificado» del mercado del día lunes condicionó aún más a un gobierno que empezó a sentir un fuerte vacío de poder y la posibilidad de un adelantamiento del traspaso de poder a sus sucesores. Game over para la teoría según la cual —en palabras del ministro de Economía Nicolás Dujovne en 2018 cuando describía el acuerdo con el FMI — «nunca se hizo un ajuste de esta magnitud sin que caiga un gobierno». El gobierno no cayó por una revuelta popular sino por el mecanismo institucional de las elecciones, condicionando a su vez al próximo gobierno con una deuda impagable.

\section{Consideraciones finales}

Esto abre una serie de interrogantes acerca de qué es y cómo se interpreta convencionalmente la llamada «debilidad institucional» de las democracias. Mientras los estudios sobre democratización tienden a asociar la debilidad institucional con el ejercicio populista, personalista y presidencialista del poder - lo que la literatura denomina «deformaciones

8 Ver, por ejemplo, las declaraciones de Roberto Lavagna en diario La Nación 27 de agosto de 2019. 
patológicas de la democracia» (Huntington, 1968), casi siempre asociadas a los países en vías de desarrollo o con democracias relativamente nuevas - poco esfuerzo se ha hecho por analizar el modo en que los mercados debilitan las instituciones democráticas tanto en el Norte como en el Sur al instaurar sistemas decisorios paralelos y de facto con más poder y capacidad de condicionar la agenda política que las instituciones formales. La capacidad coercitiva que las grandes empresas pueden ejercer sobre la democracia nunca es vista con la misma preocupación que los fantasmas de un temible líder populista. Por ejemplo, es bastante «patológico» que luego de un proceso electoral, los principales titulares mediáticos y la preocupación central de la opinión pública radique de manera excluyente en la «reacción de los mercados» o «cuánto se disparó el valor del dólar» en buena medida marcándole los límites (o dándole su veredicto) al gobierno electo. En este sentido, parece válido preguntarse ¿qué debilita más la democracia, el populismo o el capital financiero?

Más aún, ¿hasta qué punto puede ser democrático el neoliberalismo? La tremenda represión en Chile en $2020^{[9]}$ y el golpe de Estado en Bolivia ${ }^{[10]}$ abren un gran interrogante acerca de los límites democráticos de un sistema de acumulación cada vez más concentrado y excluyente. ¿Se está abriendo una nueva etapa de neoliberalismo autoritario en la región? ¿Cómo condiciona este contexto la renegociación de la deuda externa argentina para el próximo gobierno? ¿Se puede resolver esta nueva crisis de deuda (y la profunda crisis social y económica que conlleva) dentro de los márgenes de la institucionalidad democrática? Hasta ahora, la respuesta parece ser afirmativa y así lo demostró el proceso electoral que terminó canalizando pacíficamente la explosión financiera, y el hecho de que gobierne a partir del 10 de diciembre el partido peronista podría ser tomado como indicador de gobernabilidad. Sin embargo, es mucho lo que está en juego en Argentina para el establishement financiero global y no está para nada claro cuál será su estrategia ni su voluntad/capacidad de negociación, o cuánto está dispuesto a perder en pos de la democracia. Históricamente, con crisis severas y ante la disyuntiva de elegir entre democracia y capitalismo, la clase capitalista siempre eligió lo segundo.

9 Nota de la Editora: En 2019, el Movimiento al Socialismo (MAS) ha ganado las elecciones presidenciales con el candidato Luis Arce Catacora, ex ministro del gobierno de Evo Morales. En 2021, hubo las primeras elecciones presidenciales chilenas, después de las protestas masivas de 2020, dando la victoria al izquierdista y ex líder estudiantil Gabriel Boric.

10 Ver, por ejemplo, el informe del Washington Post donde se explica que las elecciones llevadas a cabo bajo el gobierno de Evo Morales no fueron un fraude y, por lo tanto, la posterior intervención claramente se trata de un golpe de Estado. http://www.washingtonpost.com/politics/2020/02/26/bolivia-dismissed-its-october-elections-fraudulent-our-research-found-no-reason-suspect-fraud 


\section{Referencias}

Arrighi, G. (2001). Workers north and south. En C. Leys and L. Panicth (eds.), The socialist register. Merlin Press, 2000.

Azpiazu, D. (2002). Privatizaciones y poder económico. La consolidación de una sociedad excluyente. Flacso/Universidad Nacional de Quilmes/IDEP.

Borón, A. (1995). State, capitalism and democracy in Latin America. Lynne Rienner Publishers.

Borón, A. (2000). Tras el búho de Minerva. Mercado contra democracia en el capitalismo de fin de sig'lo. Fondo de Cultura Económica.

Borón, A. (2006). The truth about capitalist democracy. En L. Panitch and C. Leys (eds.), Socialist register 2006: telling the truth. Merlin Press.

Brown, A. (17 de junio de 2014). Blindaje y megacanje: la mayor estafa de la historia. Orsai,

Castorina, E. (2017). Neoliberalismo democrático: una nueva forma de poder. Revista Question, 1(53), 20-36, enero-marzo.

Castorina, E. (2018). Neoliberalismo democrático y deuda externa: lecciones del caso argentino. Revista Ciencia Política, 13(25), 149-172, enero-junio, Universidad Nacional de Colombia.

Crozier, M., Huntington, S. y Watanuki, J. (1975). La crisis de la democracia. Informe a la Comisión Trilateral.

Chomsky, N. (2015). Reequiem for the American Dream. Documental.

De Angelis, M. (2003). Neoliberal governance, reproduction and accumulation. The Commoner, 7, 1-28, spring-summer. http://www.commoner.org.uk/07deangelis.pdf

Duménil, G. and Lévy, D. (2002). The nature and contradictions of neoliberalism. En L. Panitch and C. Leys, (eds.), Socialist register 2003: a world of contradictions, Merlin press.

Gill, S. (1995), Globalization, Market civilization and disciplinary neo-liebralism. En Millenium: Journal of internacional studies, 24(3).

Gill, S. (2003). Power and resistance in the new world order. Palgrave Macmillan.

Gowan, P. (1999). The g'lobal gamble. Washington's faustian bid for world dominance. Verso.

Harvey, D. (2003). The new imperialism. Oxford University Press.

Harvey, D. (2005). A brief history of neoliberalism. Oxford University Press.

Huntington, S. (1991). La tercera ola. La democratización a finales del sig'lo Xx. Paidos.

La Nación. (16 diciembre 2005). Histórico: el país saldará en un solo pago la deuda con el FMI, (nota editorial del periódico sin firma).

Observatorio de Políticas Públicas de la Universidad Nacional de Avellaneda (enero 2017). Deuda del BCRA en Lebacs. www.undaev.edu.ar

Panitch, L. (1994), Globalization and the State. En R. Miliband (ed.), Socialist register 1994: between globalism and nationalism. Merlin Press.

Panitch, L. and Gindin, S. (2004). Global capitalism and American empire. En L. Panitch and C. Leys (eds.), Socialist register 2004: the new imperial challenge. Merlin Press.

Piketty, T. (30 de noviembre 2014). Lo que sufre Argentina por el hegemonismo jurídico norteamericano es peor que la ausencia de justicia. Página 12. http://www.paginal2.com.ar/ diario/elpais/1-260940-11-30html

F. Poli. (10 de agosto 2014). El fallo del juez Thomas Grieza, la situación de la Argentina y las consecuencias para el mundo. La Nación. 
